\title{
La eficacia de la publicidad on-line \\ en el contexto de los blogs
}

\section{The effectiveness of banner ads on blogs}

\author{
Asunción Beerli Palacio ${ }^{1}$ \\ Josefa D. Martín SAntana ${ }^{2}$ \\ Universidad de Las Palmas de Gran Canaria
}

Recibido el 20 de noviembre de 2009, aceptado el 11 de enero de 2010

$\mathrm{N}^{\mathrm{o}}$ de clasificación JEL: M3

DOI: $10.5295 / \mathrm{cdg} .100186 \mathrm{ab}$

Reseña bibliográfica: BEERLI, P. y MARTÍN, J. D. (2010): "La eficacia de la publicidad on-line en el contexto de los blogs", Cuadernos de Gestión, Vol 10, no especial, pp.17-42, DOI: 10.5295/ cdg.100186ab

\section{Resumen:}

El objetivo del presente trabajo se ha centrado en medir la eficacia publicitaria de dos formatos de anuncios on-line, concretamente el robapáginas frente al contextual, así como los factores que sobre la base de la literatura revisada influyen en dicha eficacia publicitaria. Su contexto de aplicación son las páginas web de tipo blog o bitácora que, a pesar del auge que han experimentado en su utilización, no han recibido atención en el ámbito de la investigación publicitaria. Los resultados reflejan que existen diferencias en la eficacia publicitaria de ambos formatos de anuncios y que los factores que influyen en dicha eficacia son la actitud hacia el blog, la implicación con el producto anunciado y la duración de la visita en el blog.

Palabras clave:

Publicidad, eficacia publicitaria, internet, blogs.

\begin{abstract}
:
The aim of this paper is to measure the advertising effectiveness of two formats of on-line advertisements, namely, large-button advertisements and contextual advertisements, and to determine the factors which, on the basis of the reviewed literature, influence advertising effectiveness. The context of application is blog type web pages, which, despite the significant increase in their use, have not received attention in the field of the advertising research. The results reflect that there are differences in the advertising effectiveness of the two formats and that the factors that influence are attitude to the blog, involvement with the product advertised and the length of the visit to the blog.
\end{abstract}

\section{Key Words:}

Advertising, advertising effectiveness, internet, blogs.

\footnotetext{
${ }^{1}$ Universidad de Las Palmas de Gran Canaria. Facultad de Ciencias Económicas y Empresariales. Departamento de Economía y Dirección de Empresas. Edificio Departamental de Empresariales; Módulo C-1.06. Campus de Tafira. 35017 Las Palmas de Gran Canaria. e-mail: abeerli@dede.ulpgc.es

22e-mail: jmartin@dede.ulpgc.es
} 


\section{INTRODUCCIÓN}

La alta penetración de internet como medio de comunicación en la sociedad se pone de manifiesto en el importante incremento de usuarios en los últimos años. Concretamente, en España, en tan solo doce años se ha pasado del $2.7 \%$ en 1997 al $48.2 \%$ en la oleada febrero-marzo de 2009 de usuarios respecto a la población (AIMC). Esta misma tendencia se observa en la inversión publicitaria en internet, que está siendo el medio que más crecimiento está experimentando en los últimos años. Así, mientras el mercado publicitario de los medios convencionales aumentó en 2007 un 37.9\% respecto al 2000, la inversión en la red lo hizo en un $803.4 \%$ (Infoadex). Su expansión como medio de comunicación publicitaria, puede deberse, entre otras razones, al hecho de que internet es considerado como un medio en el que convergen múltiples medios, es decir, se trata de un híbrido de televisión, radio, prensa, revistas, carteles, mailing, etc. (Miller, 1996), así como a los reducidos costes asociados a la ejecución y a las inserciones publicitarias y a su capacidad para segmentar a la audiencia (San José Cabezudo, Gutiérrez Arranz y Gutiérrez Cillán, 2004). A este respecto, Leong et al. (1998) señalan que internet, en comparación con otros medios audiovisuales, es un medio más racional y con menor capacidad para suscitar emociones. Además, la privacidad (anonimato), flexibilidad (disponible 24 horas), y la posibilidad de comparar información (características del producto, precios, etc.) convierten a Internet en un medio esencial para hacer publicidad por parte de las empresas (San Martín y López, 2010).

Por otra parte, también nos encontramos estudios que ponen de manifiesto la preferencia por parte del público de la publicidad en internet respecto a la publicidad en otros medios como televisión, periódicos, revistas y radio (Yoon y Kim, 2001). Ello puede ser debido al carácter informativo e interactivo de internet como medio de comunicación (Miller, 1996), en el que el individuo ejerce una actitud totalmente activa y puede obtener cualquier tipo de información de forma rápida y sencilla. No obstante, Dahlén y Bergendahl (2001) y Chandon y Chtourou (2005) señalan que los banners son en sí mismos una forma publicitaria pasiva, ya que el internauta es expuesto a ellos sin solicitarlo; mientras que los sitios web son una forma activa de publicidad en la medida en que los usuarios de internet son los que toman la iniciativa de buscar más información, jugando en este caso los banners un papel esencial a la hora de transportar al usuario a los sitios webs a través del click. Así mismo, esta preferencia puede venir explicada por el gran dinamismo que ha habido en el diseño de los anuncios publicitarios en internet, denominados de forma genérica como banners, que ha generado una gran variedad de formatos publicitarios on-line que se pueden clasificar en función de que estén dentro de la página (banner, botón, rascacielos o skyscraper, robaráginas, streaming y publicidad contextual) o sobre la página como anuncios flotantes ( $\mathrm{y}$ anuncios flotantes).

En general, la actitud hacia la publicidad en la web es más positiva en la medida en que inspira mayor confianza y se percibe como menos irritante que la publicidad emitida en los medios convencionales, ya que la interactividad permite a los usuarios adaptar el anuncio a sus necesidades individuales, decidir leerlo o no, determinar el tiempo que se dedica a su lectura, poder acceder inmediatamente a la información y elegir libremente la página a la que desean ser expuestos (Schlosser et al., 1999). En este sentido, internet se percibe 
como un medio muy adecuado para obtener información de un producto o servicio, sobre todo en los contextos de productos de alta implicación en los que el proceso de búsqueda de información es más complicado y dilatado en el tiempo (Yoon y Kim, 2001).

Entre los principales objetivos de la publicidad en internet destacan el conseguir que el usuario haga click en el anuncio y que visite el sitio web del anunciante y permanezca en el mismo tanto tiempo como sea posible (Chandon et al., 2003). En este sentido, existe la convicción de que una de las funciones principales de los banners publicitarios es generar tráfico en los sitios web (Briggs y Hollis, 1997; Gatarski, 2002; Chandon et al., 2003; Chandon y Chtourou, 2005). Ahora bien, en la actualidad son varias las razones que explican la necesidad de evaluar la eficacia de la publicidad on-line. Por un lado, la mayor saturación publicitaria en el entorno web (Yaveroglu y Donthu, 2008) y, por otro, la existencia de una cierta tendencia por parte de los usuarios a evitar los anuncios en internet debido, principalmente, a la percepción de que los anuncios impiden leer un contenido de la web, acceder rápidamente a una página, etc. (Cho y Cheon, 2004). Ello lleva a los internautas a centrarse más en el contenido del sitio web a descartar los banners (Yaveroglu y Donthu, 2008).

Por otra parte, a partir del año 2004 surge el término Web 2.0 para referirse a un nuevo tipo de páginas web basado en las contribuciones de los usuarios y en la aportación global de conocimiento (O’Reilly, 2005). Uno de los fenómenos más representativos de la Web 2.0 es el auge del blog, cuyo término proviene de las palabras web y log, que en inglés significa diario.

Los blogs se han estudiado desde el punto de vista de la sociedad de la información y como herramientas de marketing en sí mismo. De ahí que podamos encontrar estudios sobre su uso en campos tan variados como la política, las ONGs, la empresa, etc. Sin embargo, no se han encontrado estudios sobre la eficacia de la publicidad insertada en el entorno del blog. Dada la importancia del fenómeno blog, el cual es uno de los principales representantes de la Web 2.0, se hace necesario llevar a cabo estudios que midan y comparen la eficacia publicitaria en dicho contexto. Sobre esta base se plantea la presente investigación, que tiene como principal objetivo medir la eficacia de dos formatos de publicidad (robapáginas y contextual) en blogs destinados a públicos de alta implicación y blogs destinados a públicos de baja implicación, analizando, al mismo tiempo, los factores que pueden influir en la eficacia publicitaria en el contexto del blog.

\section{REVISIÓN DE LA LITERATURA}

Desde el primer banner en 1994, dos paradigmas han caracterizado a la eficacia publicitaria: la construcción de marca y la respuesta directa, esta última medida por el ClickThrough (Chandon et al., 2003; Hollis, 2005). Bajo el primer paradigma, los banners contribuyen a mejorar la estrategia de comunicación de la empresa, que persigue como objetivos incrementar el recuerdo de la marca, la actitud hacia el anuncio y la actitud hacia la marca; mientras que bajo el segundo paradigma, al ser internet considerado como una herramienta de marketing directo, el banner se equipara a un cupón de respuesta cuya eficacia debe ser medida por su capacidad para provocar una respuesta directa, de ahí que se utilice el Click-Through Rate (en adelante CTR), como medida de eficacia (Chandon y Chtourou, 2005). 
El CTR, que es la medida basada en el número de clicks que se efectúan sobre el anuncio insertado en una página web, ha sido la medida de eficacia más utilizada para la publicidad on-line. De hecho, la mayoría de las agencias de publicidad usan los click-throughs y los modelos de resultados en ventas como indicadores de eficacia, obviando la medición de los efectos de tipo cognitivo o afectivo generados por el banner (Shen, 2002). El excesivo uso del CTR para medir la eficacia publicitaria ha sido cuestionado por algunos autores (Dreze y Hussherr, 2003; Lohtia et al, 2003; Chandon, 2003), ya que supone una respuesta activa al anuncio y no simplemente una exposición probable al mismo. Mediciones sobre la marca, como la actitud o el recuerdo, han sido relegadas a un segundo plano por debajo del CTR. En este sentido, Manchanda et al. (2006) afirman que en la literatura existe un extenso debate sobre cómo medir la efectividad del banner, el cual genera efectos de tipo actitudinal, que no pueden ser evaluados a través del CTR, que es considerado como una medida pobre de la respuesta publicitaria de los individuos al banner.

Hollis (2005), en su meta-análisis, intentó demostrar que la respuesta directa y la construcción de marca no son contradictorias sino complementarias, y que la aplicación de cada modelo depende de la audiencia y del objetivo del anuncio. De hecho, a partir del análisis de otros estudios concluye que el hacer click en un banner es una consecuencia del efecto de la construcción de marca combinado con la voluntad de saber más acerca de la marca específica como resultado de una necesidad inmediata de un producto o servicio de ese tipo. En esta línea, Chandon y Chtourou (2005) concluyen diciendo que el acto de hacer click es una parte del proceso de persuasión y que no hay necesidad de enfrentar al CTR con las medidas tradicionales de medición de la eficacia publicitaria. Estos autores consideran que el CTR es una medida idónea cuando los objetivos publicitarios son a corto plazo y cuando lo que se pretende es que el consumidor responda on-line; mientras que las medidas tradicionales de medición de la eficacia son idóneas cuando los objetivos son a más largo plazo y no se espera una respuesta de los individuos on-line.

Revisando la literatura nos encontramos, además del CTR, una gran variedad de técnicas utilizadas para medir la eficacia de la publicidad en internet, que se pueden clasificar en técnicas cognitivas, afectivas y conativas, de acuerdo con las etapas conocer-sentir-hacer de los modelos de jerarquía de efectos de la publicidad. Se trata de medidas que no difieren sustancialmente de las utilizadas en los medios convencionales, pudiéndose apreciar que la respuesta de los individuos a la publicidad on-line es muy similar a la dada en los medios convencionales, aunque es necesario estudiar la eficacia de la publicidad on-line desde un nuevo paradigma en el que se mida además de la respuesta a la información, la interacción con la misma, ya que el individuo en este nuevo entorno ejerce un papel totalmente activo (Pavlou y Stewart, 2000).

Entre las técnicas cognitivas podemos señalar que se han utilizado algunas medidas de tipo fisiológico. Entre ellas se ha hecho uso del psicogalvanómetro, que es un instrumento que permite medir el grado de secreción de las glándulas sudoríparas en el momento de la exposición del individuo a la publicidad mediante la medición del nivel de conductancia eléctrica a través de la piel. Así, por ejemplo, en el trabajo de Sundar y Kalyanaramen (2004) se utilizó el nivel de conductancia de la piel o Skin Conductance Level (SCL) para estudiar el efecto de la velocidad de animación en los anuncios web. Para ello, primero se tomó el nivel de conductancia de los participantes antes de la exposición a los anuncios, después se tomó durante la exposición de la página web con anuncios a una velocidad lenta 
y, finalmente, se tomó durante la exposición de la página web con anuncios a una mayor velocidad. Por otra parte, en España se llevó a cabo un estudio utilizando como instrumento la cámara ocular para conocer la eficacia de la publicidad on-line en prensa digital (Alt64 Digital, 2005). Este estudio, realizado con la colaboración de AIMC, que se fundamentó en el hecho de que la mirada de un ser humano es un buen indicador acerca de qué es lo que le está llamando la atención, pretendía conocer automáticamente y con mucha precisión cuál es el recorrido de la mirada, cuánto tiempo se detiene el usuario en un punto o área concreta o saber si el usuario está leyendo o escaneando un texto.

Otro de los grupos de medidas de eficacia publicitaria de carácter cognitivo ampliamente utilizado es el de las técnicas basadas en la memoria, más concretamente las medidas de recuerdo espontáneo, recuerdo sugerido y reconocimiento de los elementos del banner (nombre de la marca, el reclamo del producto y dirección del sitio web). Estas medidas de eficacia se han tomado en dos tipos de entornos muy bien diferenciados: el ficticio y el real, que han dado lugar a dos tipos de test:

- Test sobre sitio web ficticio. Así, por ejemplo, en la investigación de Danaher y Mullarkey (2003), en la que se estudió el efecto de la duración de la exposición en el recuerdo y en el reconocimiento en una muestra de estudiantes, se diseñó un sitio web que debería representar un nuevo portal para estudiantes universitarios. Esta alternativa es idónea cuando lo que se pretende es estudiar cómo influye la variación de uno o varios elementos en la eficacia publicitaria, ya que es posible realizar los cambios necesarios tanto en el sitio web como en los anuncios utilizados para la experimentación. Así, se puede dar el caso de un mismo sitio web con diferente selección de banners (cambiando el color, temática, texto, etc.) como en el estudio de Moore et al. (2005), o combinación de sitios web y banners como en la investigación de Shamdasani et al. (2001).

- Test sobre sitio web real. Así, por ejemplo, en el experimento de Gong y Maddox (2003), una vez el visitante accedía al sitio web se le invitaba inmediatamente a participar en un cuestionario y si aceptaba se le asignaba a una página web con uno de los banners del experimento. En el trabajo de Hollis (2005), los usuarios, sin saber que estaban formando parte de un experimento, navegan en el sitio web, de manera que cuando salían de la página web o terminaban de ver un anuncio del tipo streaming, surgía un pop-under solicitando la participación en la encuesta. Cuando se precisa conocer cómo afecta la exposición de la web y de sus anuncios, se puede realizar un cuestionario antes y después de la visita a la web mediante pop-ups, como por ejemplo, en el estudio de Dahlen et al. (2003). Si bien, en este experimento, los participantes antes de la medida y los de después de la medida eran distintos con el fin de que los segundos no se vieran influidos por el cuestionario previo.

Las medidas basadas en la actitud utilizadas para medir la eficacia de la publicidad en internet son similares a las empleadas en los medios convencionales: liking, actitud hacia el anuncio y actitud hacia la marca.

Entre las medidas de eficacia de carácter conativo utilizadas en internet, es el ClickThrough Rate (CTR) o proporción de clicks la más ampliamente utilizada y mide la frecuencia con la que los usuarios de una página hacen un click sobre un anuncio, enlazando de esta manera al navegante con el anunciante. El CTR se obtiene dividiendo el número de usuarios que hicieron click en un anuncio en una página web por el número de veces que 
el anuncio ha sido presentado (impresiones). Este indicador considera que una de las funciones del anuncio es llamar la atención del usuario y llevarle al sitio web del anunciante. El hacer click en un banner es una reacción a corto plazo que implica una decisión impulsiva y que es más probable entre los buscadores activos de información. Según el metaanálisis de Hollis (2005), el hacer click "es un indicador de respuesta del comportamiento de un deseo de examinar reclamos realizados en el anuncio para averiguar su relevancia o su veracidad". Esta acción instantánea y medible de manera automática genera un indicador que es la aportación del medio internet a las medidas de eficacia publicitaria de los medios tradicionales. Si bien existe cierto debate sobre si el CTR es una buena medida de la eficacia publicitaria, las principales ventajas de este indicador se centran en que mide la acción voluntaria del cliente potencial que está buscando información suplementaria, su recopilación está automatizada y no requiere de la realización de encuestas a usuarios (Chandon et al., 2003). Como principales inconvenientes que se asocian al CTR destacan el hecho de que no mide todos los aspectos de la eficacia publicitaria ni cubre todos los objetivos que un anunciante puede asignar al anuncio en la web. Además, mide sólo efectos a corto plazo y sólo contempla que el individuo es impactado inmediatamente a la exposición, pero no recoge el hecho de que el usuario que ha sido expuesto consulte la web algún tiempo después (Chandon et al., 2003). Otra posible alternativa para medir la eficacia de un anuncio a nivel conativo es la intención de compra generada por el anuncio, que mide la probabilidad de que un individuo compre o pruebe la marca en un futuro próximo como consecuencia de su exposición al anuncio. En el medio internet, George (2002) verificó empíricamente que la decisión de compra depende de la privacidad, la confianza en la seguridad de las transacciones y la experiencia que se tenga como usuario de internet. Finalmente, la intención de hacer click es otra posible medida conativa que ha sido utilizada en el estudio de Shamdasani et al. (2001).

Debido a la carencia de estudios comparativos de eficacia publicitaria basados en medidas cognoscitivas, afectivas y conativas que no sean CTR entre los tipos de banner objeto de estudio (robapáginas versus contextual) en una página web tipo blog o bitácora, no existe un soporte científico que nos haga suponer que un formato obtiene mejores resultados que el otro. No obstante, en el trabajo de Danaher et al. (2006), realizado en el contexto de páginas web como publicidad institucional, se demostró que la duración de la visita a un sitio web, considerada en este caso como una medida conativa de eficacia, se ve influenciada negativamente por la mayor existencia de contenido verbal y positivamente por la mayor cantidad de contenido visual. Sobre esta base y extrapolando estos resultados a nuestra investigación en la que el robapáginas es un formato tipo banner en el que se combina el texto con imágenes y el contextual contiene únicamente texto, se plantea como hipótesis la siguiente:

H1: En un blog el formato de anuncios robapáginas presenta mejores resultados de eficacia publicitaria en términos cognitivos, afectivos y conativos que el formato contextual.

En la literatura sobre publicidad on line se recoge un conjunto de factores que afectan a la eficacia publicitaria del anuncio on-line. Estos factores suelen ser las variables independientes de los estudios que analizan la eficacia publicitaria en internet y están relacionados principalmente con el contenido y el diseño del banner y del sitio web. También nos podemos encontrar otros factores tales como el grado de implicación con los productos de los sitios web y la duración de la visita en el sitio web. 
En relación al contenido y al diseño del banner, los principales estudios se han basado en el modelo ELM (Elaboration Likelihood Model) de Petty y Cacioppo (1986) que establece que las personas tienden a procesar información dependiendo de su nivel de implicación con el mensaje. Basándose en este modelo, se han realizado diferentes estudios que han tratado de demostrar la influencia del nivel de implicación con el contenido del banner sobre la eficacia de los anuncios en internet (Lohtia et al., 2003; Shamdasani et al., 2001, Gong y Maddox, 2003; Danaher y Mullarkey, 2003). Lohtia et al. (2003) apuntan como elementos del contenido del banner el mensaje y la existencia de reclamos, así como la utilización de atributos de tipo emocional con los que se persigue captar la atención de los internautas al despertar en ellos emociones tales como miedo, felicidad y alegría. En este sentido, Lohtia et al. (2003) apuntaban que la existencia de incentivos en un banner, por ejemplo, ofrecer un descuento por hacer click en el banner, puede llegar a generar en el internauta la respuesta deseada (el click), hipótesis que no pudieron contrastar empíricamente. Por otra parte, también es importante para el éxito del banner, que éste genere curiosidad entre los internautas (Menon y Soman, 2002). Centrándonos más en el contenido del mensaje, Hupfer y Grey (2005) afirman que lo que un anuncio dice es más importante que cómo se dice, por lo que es necesario cuidar con detalle el contenido de un anuncio interactivo. Esta afirmación se corrobora en el trabajo de Robinson et al. (2007), en el que se pone de manifiesto que los mensajes largos en los banners generan mayores niveles de clicks.

En lo que al diseño del banner se refiere, existen múltiples trabajos empíricos que han demostrado que la localización, la repetición, el contraste, la forma, la interactividad, el color y la animación son elementos del diseño de un banner que influyen en su éxito (Baltas, 2003; Lohtia et al., 2003; Moore et al., 2005; Chandon et al., 2003; Chandon y Chtourou, 2005, Cheung, 2006; Sundar y Kalyanaraman, 2004; Hupfer y Grey, 2005; Robinson et al., 2007; Yaveroglu y Donthu, 2008). Al contrario de lo que ocurre en los medios convencionales, el efecto del tamaño del banner en su eficacia no es concluyente al existir estudios con resultados antagónicos (Chtourou et al., 2001; Baltas, 2003; Chandon et al., 2003; Chandon y Chtourou, 2005; Cho, 2003; Drèze y Hussherr, 2003; Hupfer y Grey, 2005; Robinson et al., 2007). Finalmente, la actitud hacia el formato del anuncio on-line, definido como la forma en la que el anuncio aparace, se ha demostrado que ejerce una fuerte influencia en la respuesta conativa de los internautas (CTR), en la medida en que las percepciones de los individuos hacia los diferentes tipos de formato son diferentes en términos de entretenimiento, información y molestia de cada uno de estos formatos para el internauta (Burns y Lutz, 2006).

En lo que al diseño de la página web se refiere, Lee y Thorson (2009) señalan que dado que los banners se colocan en una página web, existe una probabilidad elevada de que las características y contenidos de la página web tengan un elevado impacto en el procesamiento de los anuncios de banners. En este contexto, en el experimento de Stevenson et al. (2000) se llegó a la conclusión de que la simplicidad frente a la complejidad tiene un efecto positivo en las actitudes hacia el anuncio y hacia la marca, en la intención de compra y en la actitud hacia el sitio web. Estos autores señalan que a pesar de que la complejidad ejerce una influencia negativa en las variables anteriores, no afecta a la atención. No obstante, y respecto a las medidas de memoria, en el estudio de Danaher y Mullarkey (2003) se demostró que la complejidad tanto del contenido como del fondo no afecta al recuerdo 
ni al reconocimiento del anuncio. Por otro lado, tal y como ocurre en los medios convencionales, en internet un mismo anuncio con una misma audiencia puede generar diferentes efectos cuando aparece en distintos soportes debido, entre otros aspectos, a la credibilidad o reputación de la página web en la que se inserta, ya que la reputación de la página web puede crear inferencias en el usuario acerca de la calidad del contenido y los anuncios del website. Por tanto, si tenemos presente que el contenido y el diseño de un blog destinado a públicos de alta implicación es notablemente diferente frente a uno destinado a públicos de baja implicación, cabe esperar la existencia de diferencias en la eficacia de los anuncios insertados en ambos, dada la influencia que ejerce el entorno en el que se insertan los anuncios. Es por ello que se plantea como hipótesis la siguiente:

H2: En un blog de alta implicación los formatos de anuncios robapáginas y contextual obtienen mejores resultados de eficacia publicitaria en términos cognitivos, afectivos y conativos que en un blog de baja implicación.

Por otra parte, las características del sitio web son también determinantes en la eficacia de los banners. Algunos estudios han extendido el paradigma de la actitud hacia la marca al campo del comercio electrónico, creando el concepto de actitud hacia el sitio web. De esta manera, hay ciertas evidencias que ponen de manifiesto que la actitud hacia el sitio web influye positivamente en la actitud hacia el anuncio, la marca y la intención de compra (Stevenson et al., 2000). Además, según el estudio de Goldsmith y Lafferty (2002), los consumidores que tienen una respuesta favorable al sitio web es más probable que recuerden marcas anunciadas en la web que los que no la tienen. Sobre la base de estos resultados se plantean como hipótesis las siguientes:

H3: Existen diferencias en la actitud hacia el sitio web del blog en función del entorno de alta o baja implicación del blog.

H4: La actitud hacia el sitio web del blog tiene una relación significativa y positiva con las medidas cognitivas, afectivas y conativas de la eficacia publicitaria de los anuncios.

En lo que al grado de implicación con los productos de los sitios web se refiere, es de destacar que los productos de alta implicación requieren de una audiencia dispuesta a invertir más tiempo en buscar y procesar la información. Ello implica que los anuncios de productos de alta implicación (que siguen la ruta central del modelo ELM) deberían ser procesados durante más tiempo y más activamente que los de baja implicación (que siguen la ruta periférica del modelo ELM). Según los estudios de Dahlén (2002) y Dahlén et al. (2003), dependiendo del tipo de producto del website, el nivel de exposición y el número de clicks variarán, lo cual podría afectar a la eficacia de un anuncio que se encuentre en dicha web. De esta forma, las webs de productos con alta implicación obtienen una mayor exposición y generan más clicks. Esto ocurre principalmente en la primera visita, ya que las siguientes visitas son más cortas y menos activas debido a que a los usuarios les costará menos procesar la información. Sin embargo, si los visitantes repiten en una web de productos de baja implicación, su exposición será más larga y generará más clicks que la primera vez, ya que si repiten es porque les entretuvo la primera vez los elementos periféricos (juegos, elementos audiovisuales, animaciones, etc.). En esta misma línea de investigación, Dahlén y Bergendahl (2001) demostraron que los anuncios de productos racionales 
o funcionales tiene una ratio de clicks que es el doble que la de los productos emocionales, ya que los productos racionales están sujetos a una mayor búsqueda de información y esfuerzo cognitivo. Dahlén (2002) da un paso más allá y demuestra empíricamente que en los productos racionales la ratio de clicks decrece con la repetición, ocurriendo todo lo contario con los productos emocionales. Respecto a la actitud hacia la marca, el hecho de que el visitante tenga la posibilidad de buscar información interesante e interactúe con el producto hace que la visita a un sitio web de productos de alta implicación aumente la actitud hacia la marca. No obstante, el efecto repetición ejerce un papel moderador en esta influencia como queda demostrado en el estudio de Dahlén (2002), el que se confirma que para los productos racionales la actitud hacia la marca no se incrementa con la repetición de los banners, pero sí con los productos emocionales.

Por otra parte, y dejando de lado el efecto de la tipología de producto y centrándonos más en el individuo, en los trabajos de Chtourou et al. (2001) y Pieters y Wedel (2004) se afirma que la implicación o el grado de interés de los internautas con los productos anunciados, así como la familiaridad con las marcas anunciadas estimulan a los individuos a prestar más atención a los anuncios y a sus elementos. En esta línea, en el trabajo de Cho (2003) se demuestra que los individuos que están más involucrados con el producto anunciado en el banner tienden a hacer click en mayor proporción que los que no lo están. Estas investigaciones han permitido formular la siguiente hipótesis:

H5: El grado de implicación de un visitante con el producto del anuncio situado en un blog tiene una relación significativa y positiva con las medidas cognitivas, afectivas y conativas de la eficacia publicitaria de los anuncios.

Por otra parte, a priori se puede llegar a pensar que cuanto más familiarizados estén los internautas con el medio, más fácilmente aprenderán a diferenciar el contenido informativo del publicitario y de esta forma reducir su eficacia. Esta hipótesis queda avalada por el trabajo de Drèze y Hussherr (1999), en el que se demuestra que los usuarios de internet evitan mirar los anuncios, son capaces de reconocer que un elemento es un anuncio sin tener que mirarlo directamente y que los más expertos tienden a procesar cada página más rápidamente que los menos experimentados, no observándose diferencias en función del género, pero sí en la edad; por el de Dahlen (2001), en el que se pone de manifiesto que los usuarios más experimentados con internet son menos susceptibles a los banners que los más novatos; así como por el de Dréze y Hussher (2003), en el que se llega a la conclusión de que, a través de una experimentación realizada con una cámara ocular, la familiaridad con las prácticas publicitarias en internet ha contribuido a la capacidad de los internautas para ignorar las áreas donde se localizan habitualmente los banners. Así mismo, en uno de los resultados del estudio realizado por Alt64 Digital, en colaboración con AIMC en 2005, se llegó a la conclusión de que la experiencia del individuo como internauta y su hábito de lectura de diarios on-line no influían en si fijaba o no su mirada en los anuncios publicitarios. Sobre la base de estos resultados se plantean estas dos hipótesis de trabajo:

H6: El grado de uso de internet por parte del internauta no influye de forma significativa en las medidas cognitivas de la eficacia de los anuncios. 
H7: El grado de uso de páginas web tipo blog o bitácora por parte del internauta no influye de forma significativa en las medidas cognitivas de la eficacia de los anuncios.

Finalmente y siguiendo a Danaher y Mullarkey (2003), la duración de la visita en el sitio web es otro de los factores a considerar en la eficacia de la publicidad on-line, ya que cuanto mayor sea dicha duración más probable será la exposición de los internautas a la publicidad insertada en el sitio web. En su estudio, estos autores demostraron que cuanto mayor es la duración de la visita mayor es el nivel de recuerdo espontáneo de la publicidad insertada en la página. De hecho, cuantificaron que duraciones de 20, 40 y 60 segundos daban lugar a niveles de recuerdo del $26 \%, 43 \%$ y $50 \%$, respectivamente. No obstante y a pesar de este efecto positivo de la duración de la visita sobre la eficacia publicitaria, Danaher et al. (2006) demostraron que cuanto mayor es el nivel de publicidad existente en un sitio web menor es la duración de la visita, de ahí que la saturación publicitaria, como ocurre en los medios convencionales, es un elemento distorsionador de la eficacia de los anuncios on-line. En este estudio se llegó a la conclusión de que aquellos sitios web con seis o más anuncios por página provocan en sus visitantes un efecto huída, aunque ello depende de la edad del internauta. Sobre la base de estas investigaciones, en el presente trabajo se plantea como última hipótesis la siguiente:

H8: El grado de duración de la visita al blog tiene una relación significativa y positiva con las medidas cognitivas, afectivas y conativas de la eficacia publicitaria de los anuncios.

\section{METODOLOGÍA}

El procedimiento metodológico seguido en la presente investigación se basó en un diseño experimental $2 \times 2$ en el que se combinaron dos blogs destinados a públicos con diferente implicación (alta/baja) y dos formatos de anuncios on-line que se han escogido por su importancia y por pertenecer a grupos de formatos distintos: robapáginas y contextual. A tal efecto, se diseñaron cuatro blogs relacionados con productos tecnológicos y cuyos contenidos están basados en publicaciones reales, pero sin elementos o personajes que pudieran ser reconocidos por los participantes. Los participantes se asignaron aleatoriamente a una de las cuatro variaciones del blog y navegaron libremente el tiempo que consideraron oportuno. Posteriormente, se les pasó un cuestionario totalmente estructurado como instrumento de recogida de información que contestaron después de navegar por el blog.

El universo lo constituyeron personas de más de 14 años que fuesen navegantes de la web con el fin de ser una audiencia objetiva potencial de un anuncio. La selección muestral se realizó en los hogares de los individuos utilizando el método de relaciones, ya que se requería una colaboración muy estrecha por parte de los encuestados que debían utilizar su ordenador para navegar en el blog experimental. No obstante, y de forma adicional se aplicaron cuotas de acuerdo con el perfil del internatura (AIMC, 2007), con afijación proporcional al sexo y a la edad. El número total de personas que constituyeron la muestra ascendió a 868, realizándose el trabajo de campo en los meses de noviembre y diciembre de 2008. En la tabla 1 se detallan las características de la muestra. 
Tabla 1

Distribución de la muestra

\begin{tabular}{|c|c|c|c|c|c|}
\hline CARACTERÍSTICA & $\mathrm{n}$ & $\%$ & CARACTERÍSTICA & $\mathrm{n}$ & $\%$ \\
\hline GÉNERO & & & CLASE SOCIAL & & \\
\hline Hombre & 480 & 55.3 & Alta & 57 & 6.6 \\
\hline Mujer & 388 & 44.7 & Media-alta & 165 & 19.0 \\
\hline EDAD & & & Media-media & 366 & 42.2 \\
\hline De 14 a 19 años & 88 & 10.1 & Media-baja & 219 & 25.2 \\
\hline De 20 a 24 años & 184 & 21.2 & Baja & 42 & 4.8 \\
\hline De 25 a 35 años & 319 & 36.8 & FRECUENCIA ACCESO INTERNET & & \\
\hline De 35 a 44 años & 108 & 12.4 & Nunca o casi nunca & 85 & 9.8 \\
\hline De 45 a 54 años & 128 & 14.7 & Una o varias veces al mes & 102 & 11.8 \\
\hline De 55 a 64 años & 34 & 3.9 & Varias veces a la semana & 138 & 15.9 \\
\hline Más de 64 años & 6 & 0.7 & Todos o casi todos los días & 240 & 27.6 \\
\hline NIVEL DE ESTUDIOS & & & Varias veces al día & 303 & 34.9 \\
\hline Sin estudios & 7 & 0.8 & FRECUENCIA CONSULTA BLOG & & \\
\hline Primarios & 164 & 18.9 & Nunca o casi nunca & 366 & 42.2 \\
\hline Secundarios & 361 & 41.6 & Menos de una vez al mes & 95 & 10.9 \\
\hline Universitarios medios & 162 & 18.7 & Una o varias veces al mes & 144 & 16.6 \\
\hline \multirow[t]{2}{*}{ Universitarios superiores } & 174 & 20.0 & Una o varias veces a la semana & 165 & 19.0 \\
\hline & & & Casi todos los días & 97 & 11.2 \\
\hline
\end{tabular}

El contexto en el que se encuadra la presente investigación es el que a continuación se detalla.

- Soporte de comunicación. Se ha seleccionado el blog como soporte de comunicación por el elevado impacto que está teniendo en los últimos años en el ámbito de la web y por la falta de estudios sobre eficacia publicitaria. Atendiendo al ranking de blogs más visitados de Alianzo (2007), se escogió como tema del blog la tecnología, aunque enfocada a gadgets, ya que el tema permitía tratarse tanto de forma sencilla con imágenes y vídeos como en profundidad con textos explicativos. A tal efecto, se diseñaron dos blogs relacionados con nuevos cachivaches tecnológicos: (1) blog destinados a públicos con alta implicación, caracterizado por mucho texto, que requiere de un esfuerzo cognitivo para asimilar los mensajes y (2) blog destinado a públicos con baja implicación, basado en contenidos dinámicos como videos y fotos, que requiere un esfuerzo cognitivo mínimo, primando los componentes afectivos. En la figura 1 se recoge un pantallazo de cada uno de los blogs. 
Figura 1

Blogs de alta y baja implicación

ALTA IMPLICACIÓN

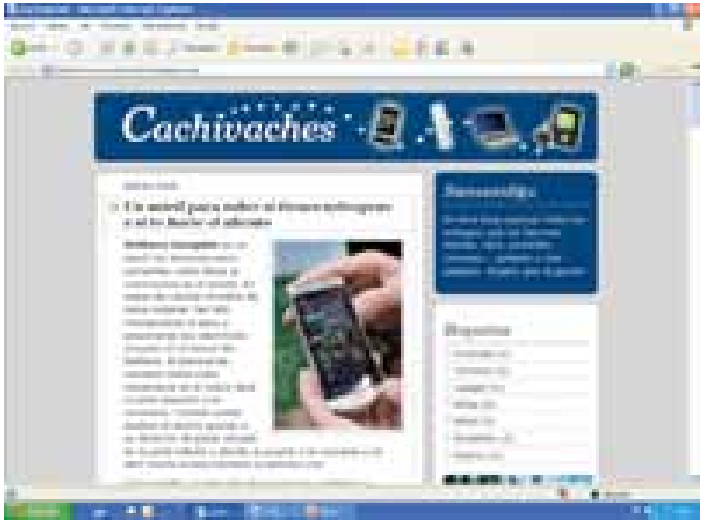

BAJA IMPLICACIÓN

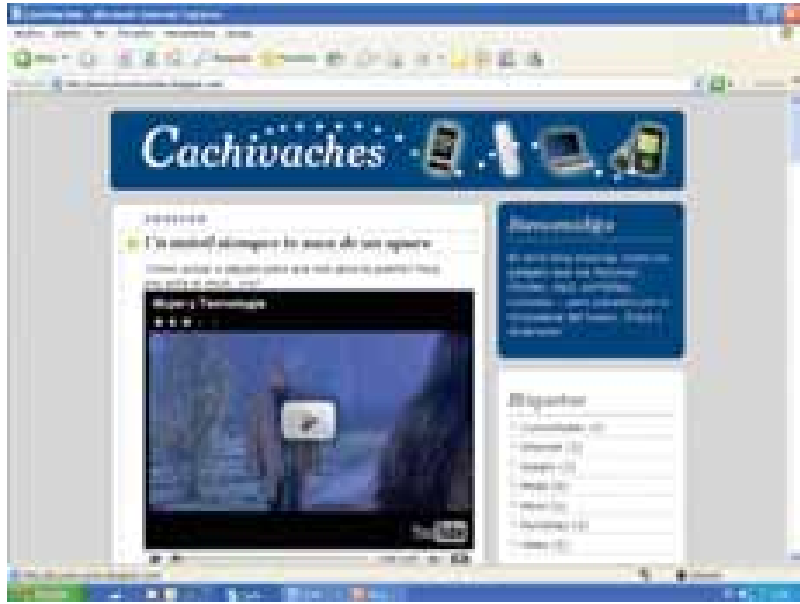

- Producto anunciado. Se utilizó un marco de fotos digital por ser un producto congruente con el tema del blog, con la marca ficticia PhotoTek.

- Estímulos publicitarios. Se utilizaron dos tipos de anuncios o formatos publicitarios: (1) robapáginas, que se corresponde con un formato dentro de la página situado en el contenido donde deberían ir gráficos o imágenes y que ocupan más espacio que el tradicional banner con una dimensión de 300x250 pixeles y (2) publicidad contextual, que es un destacado de texto similares a los patrocinios de los motores de búsqueda que mediante una tecnología de orientación por palabras se introducen en páginas web de contenidos. Los anuncios objetivos (robapáginas y contextual) 
se diseñarán en tecnología flash siguiendo los criterios que generen un mayor recuerdo. Desde el punto de vista del diseño estético se optará por incorporar niveles medios de color (Lohtia et al., 2003) y animación (Chandon et al., 2003; Cheung, 2006). Desde la perspectiva del mensaje, se introdujeron elementos que generaron curiosidad, concretamente la existencia de una oferta (Menon y Soman, 2002). Tanto el anuncio robapáginas como el contextual anunciaban el mismo producto y marca ficticia y presentaban los mismos elementos de diseño y de mensaje (véase figura 2).

Figura 2

Anuncios utilizados en el diseño experimental

ROBAPÁGINAS

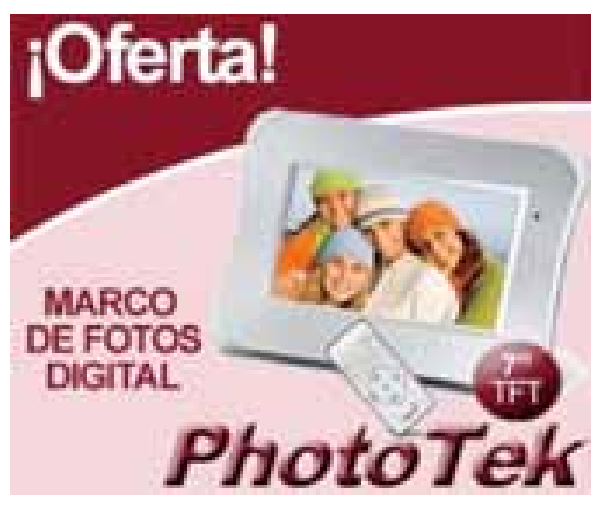

CONTEXTUAL

¡Oferta! Antes $85 €$, ahora $59 €$.

Para 1000 fotos.

Pantalla TFT de 7

wnw.photo-tek.com

Al objeto de analizar la eficacia de los anuncios en los dos formatos se utilizaron las siguientes medidas de carácter cognitivo, afectivo y conativo, cuyos ítems se recogen en la tabla 2:

- Recuerdo espontáneo de la categoría de producto, marca y características del anuncio a través de preguntas abiertas. A partir de la información obtenida, se creó una nueva variable que se ha etiquetado como "Intensidad del recuerdo espontáneo".

- Recuerdo sugerido de la marca y características del anuncio sugiriendo categoría de producto a través de preguntas abiertas. Al igual que para el recuerdo espontáneo, en este caso también se creó una nueva variable que se ha etiquetado como "Intensidad del recuerdo sugerido".

- Reconocimiento de la marca y el anuncio, utilizando como medida un test de reconocimiento de elección forzada de cuatro alternativas (una de ellas real y las tres restantes ficticias), al objeto de evitar los problemas derivados de un test de reconocimiento sí/no.

- Actitud hacia el anuncio, utilizando una escala tipo Likert de 7 puntos y 4 ítems. 
- Actitud hacia la marca, utilizando una escala tipo Likert de 7 puntos y 4 ítems.

- Actitud hacia el blog, utilizando una escala tipo Likert de 7 puntos y 6 ítems. Para el diseño de esta escala se tomó como base el estudio realizado por Newman et al. (2004) en el que se mide la actitud hacia el sitio web en sus tres dimensiones: entretenimiento, carácter informativo y organización.

- Intención de compra, utilizando una escala de un único ítem tipo Likert de 7 puntos que mide el grado en que se comprarían en la próxima compra el marco de fotos digital anunciado.

- También se incluyeron variables relacionadas con la frecuencia de acceso a internet y la frecuencia de consulta de páginas tipo blog o bitácora en una escala ordinal. Igualmente, se midió la implicación con el producto a través de una escala tipo Likert de 7 puntos y 1 ítem que mide el interés por el producto. Por último, se midió el tiempo que duró la visita al blog a través de una escala ordinal cuyas categorías de variación fueron 5 minutos o menos, entre 6 y 10 minutos y 11 ó más minutos.

Tabla 2

\section{Ítems definitivos de las escalas de medida utilizadas}

\section{Intensidad del Recuerdo Espontáneo}

\begin{tabular}{l|l}
1 & No se recuerda nada \\
2 & Sólo se recuerda la categoría de producto o la marca \\
3 & $\begin{array}{l}\text { Se recuerda la categoría de producto y se describe el mensaje o el diseño del anuncio de } \\
\text { una forma completa o regular }\end{array}$ \\
4 & \begin{tabular}{l} 
Se recuerda la categoría de producto y la marca \\
\hline
\end{tabular}
\end{tabular}

\section{Intensidad del Recuerdo Sugerido}

$1 \quad$ No se recuerda ningún anuncio de la categoría de producto sugerida

2 Se describe el mensaje o el diseño del anuncio de una forma completa o regular

$3 \quad$ Se recuerda la marca anunciada

\begin{tabular}{c|l}
\hline \multicolumn{2}{l}{ Reconocimiento } \\
\hline 1 & No se reconoce ni la marca ni el anuncio entre las alternativas mostradas \\
2 & Se reconoce la marca anunciada o el anuncio entre las alternativas mostradas \\
3 & Se reconoce la marca anunciada y el anuncio entre las alternativas mostradas \\
\hline
\end{tabular}

\section{Actitud hacia el Anuncio}

V19 Es un anuncio atractivo

V20 Es un anuncio interesante

V21 Es un anuncio creíble

V22 Este anuncio llama la atención 


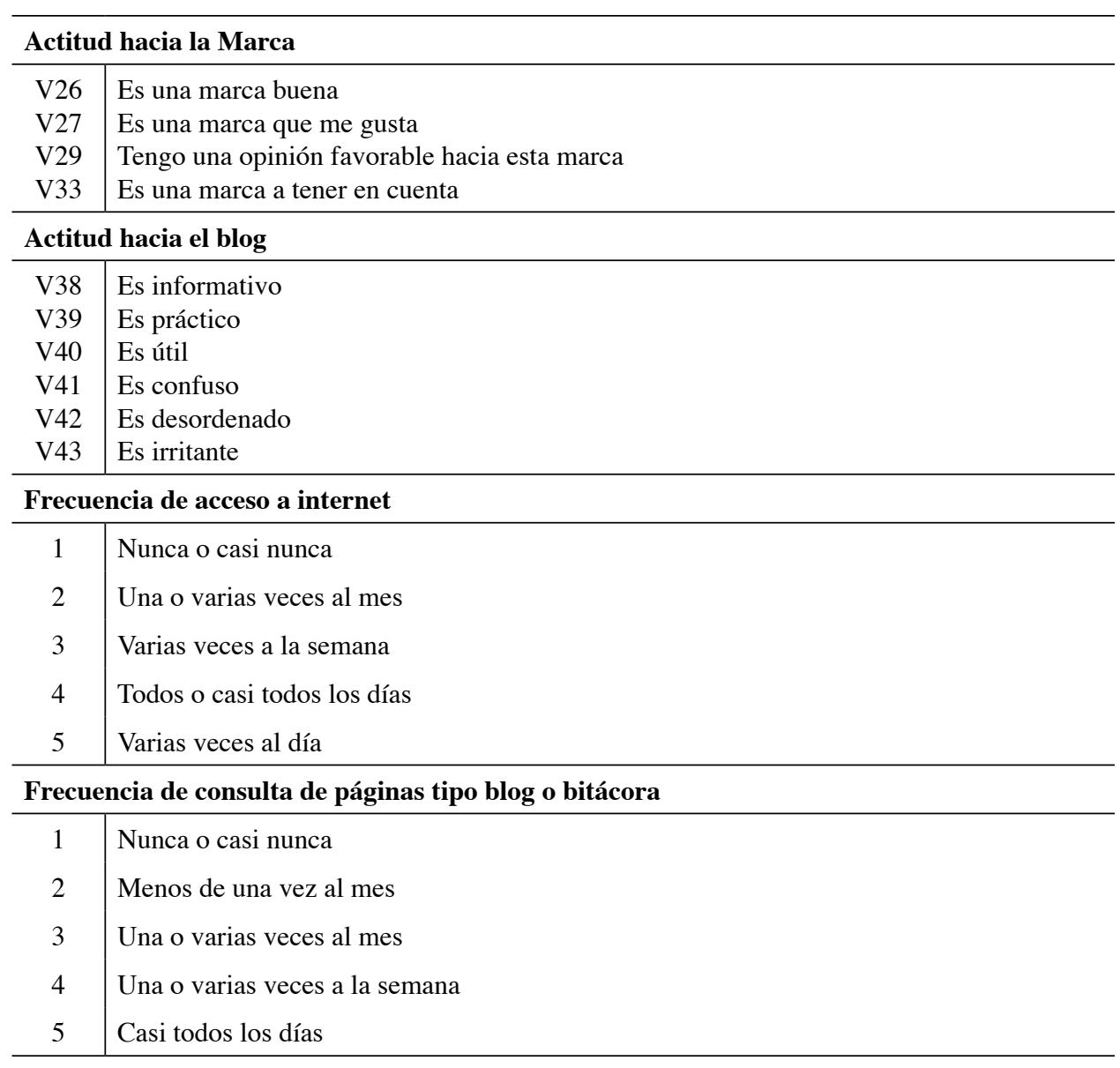

\section{ANÁLISIS DE RESULTADOS}

Antes de proceder a realizar los análisis pertinentes para el cumplimiento de los objetivos que se plantean con la presente investigación, se procedió a analizar la validez y fiabilidad de las escalas de medida utilizadas. A tal objeto, se aplicó, en primer lugar, análisis factoriales exploratorios para depurar y conocer la naturaleza dimensional de las escalas; en segundo lugar, análisis factoriales confirmatorios con el propósito de confirmar los resultados obtenidos, utilizando para ello ecuaciones lineales estructurales, y, finalmente, el coeficiente de fiabilidad compuesta y el análisis de la varianza extraída para evaluar la fiabilidad de las escalas empleadas, cuyos niveles superaban en todos los casos los valores recomendados. En las tablas 3, 4 y 5 se recogen los resultados de los análisis factoriales confirmatorios de cada una de las escalas de medidas multi-ítems, pudiéndose comprobar que los indicadores de bondad del ajuste son aceptables, dado que todas las medidas de ajuste absoluto, incremental y de parsimonia se sitúan alrededor de los límites recomendados en la literatura y que todos los pesos de regresión estandari- 
zados presentan razones críticas superiores al valor recomendado de +1.96 . Así mismo, dichos resultados ponen de manifiesto que tanto la actitud hacia el anuncio como la actitud hacia la marca son de naturaleza unidimensional y que la actitud hacia el blog es bidimensional, integrada por dos componentes relacionados con el carácter informativo del blog y su organización.

Tabla 3

Resultados del modelo de medida de la actitud hacia el anuncio

\begin{tabular}{llcccc}
\hline & Relaciones causales & $\begin{array}{c}\text { Estimadores } \\
\text { Estandarizados }\end{array}$ & $\begin{array}{c}\text { Razones } \\
\text { Críticas }\end{array}$ & $p$ \\
\hline V19 & $<---$ & Actitud hacia el anuncio & 0.837 & & \\
V20 & $<---$ & Actitud hacia el anuncio & 0.646 & 17.406 & 0.000 \\
V21 & $<---$ & Actitud hacia el anuncio & 0.299 & 8.039 & 0.000 \\
V22 & $<---$ & Actitud hacia el anuncio & 0.786 & 19.287 & 0.000 \\
\hline
\end{tabular}

Indicadores de bondad de ajuste

$\mathrm{CMIN}=5.860(\mathrm{p}=0.053), \mathrm{CFI}=0.996, \mathrm{RMSEA}=0.047, \mathrm{TLI}=0.987, \mathrm{NFI}=0.994$

$\mathrm{PCFI}=0.332, \mathrm{CMINDF}=2.930, \mathrm{PNFI}=0.331, \mathrm{AIC}=29.860$

\section{Indicadores de fiabilidad}

Fiabilidad compuesta $=0.752$

Varianza extraída $=0.456$

Tabla 4

Resultados del modelo de medida de la actitud hacia la marca

\begin{tabular}{lllccc}
\hline & & Relaciones causales & $\begin{array}{c}\text { Estimadores } \\
\text { Estandarizados }\end{array}$ & $\begin{array}{c}\text { Razones } \\
\text { Críticas }\end{array}$ & $p$ \\
\hline V26 & $<---$ & Actitud hacia la marca & 0.815 & & \\
V27 & $<---$ & Actitud hacia la marca & 0.899 & 28.220 & 0.000 \\
V29 & $<---$ & Actitud hacia la marca & 0.860 & 26.960 & 0.000 \\
V33 & $<---$ & Actitud hacia la marca & 0.685 & 20.209 & 0.000 \\
\hline
\end{tabular}

\section{Indicadores de bondad de ajuste}

$\mathrm{CMIN}=10.206(\mathrm{p}=0.006), \mathrm{CFI}=0.995, \mathrm{RMSEA}=0.069, \mathrm{TLI}=0.977, \mathrm{NFI}=0.994$

PCFI $=0.199$, CMINDF $=5.103$, PNFI $=0,199$, AIC $=34.206$

\section{Indicadores de fiabilidad}

Fiabilidad compuesta $=0.890$

Varianza extraída $=0.670$ 
Tabla 5

Resultados del modelo de medida de la actitud hacia el blog

\begin{tabular}{lllccc}
\hline & & Relaciones causales & $\begin{array}{c}\text { Estimadores } \\
\text { Estandarizados }\end{array}$ & $\begin{array}{c}\text { Razones } \\
\text { Críticas }\end{array}$ & $p$ \\
\hline V38 & $<---$ & Información & 0.741 & 24.789 & 0.000 \\
V39 & $<---$ & Información & 0.897 & 29.432 & 0.000 \\
V40 & $<---$ & Información & 0.870 & & \\
V41 & $<---$ & Organización & 0.717 & & \\
V42 & $<---$ & Organización & 0.757 & 13.417 & 0.000 \\
V43 & $<---$ & Organización & 0.561 & 12.805 & 0.000 \\
\hline
\end{tabular}

Indicadores de bondad de ajuste

$\mathrm{CMIN}=8.789(\mathrm{p}=0.360), \mathrm{CFI}=1.000, \mathrm{RMSEA}=0.011, \mathrm{TLI}=0.999, \mathrm{NFI}=0.996$

$\mathrm{PCFI}=0.381, \mathrm{CMINDF}=1.099, \mathrm{PNFI}=0.379, \mathrm{AIC}=46.789$

\section{Indicadores de fiabilidad}

Fiabilidad compuesta $=0.892$

Varianza extraída $=0.585$

Una vez comprobadas las propiedades psicométricas de las escalas de medida utilizadas, se ha procedido a contrastar la primera hipótesis a través de un ANOVA entre las medidas de eficacia publicitaria utilizadas en este estudio y el tipo de formato publicitario utilizado (robapáginas versus contextual), cuyos resultados se recogen en la tabla 6. Como se puede observar, los niveles de las diferentes medidas de eficacia publicitaria utilizadas en este estudio muestran que, en general, el formato robapágina es más efectivo. De hecho, salvo en la intensidad del recuerdo sugerido y en la intención de compra, se aprecia la existencia de diferencias significativas en los niveles alcanzados en las restantes medidas de eficacia publicitaria en función del formato publicitario utilizado. Estos resultados nos permiten afirmar que en el entorno de internet los formatos en los que se combinan textos e imágenes generan un mayor nivel de recuerdo espontáneo, una mejor identificación de la marca anunciada y del anuncio, así como unas actitudes más positivas hacia el anuncio y hacia la marca. De todas estas medidas, es la actitud hacia el anuncio la que mayor diferencia presenta, lo que nos pone de manifiesto que el formato robápaginas es capaz de generar en el individuo una evaluación más positiva del anuncio en términos de atractivo, interés que despierta, credibilidad y captación de la atención. Sobre la base de estos resultados, se puede afirmar que la hipótesis H1 se ha contrastado de forma satisfactoria, ya que los análisis arrojan como resultado que en un blog los formatos de anuncios robapáginas y contextual presentan diferencias en eficacia publicitaria en términos cognitivos, y afectivos, aunque no en términos conativos, obteniendo mejores resultados el formato robapáginas que el contextual. Estos resultados vienen a corroborar en cierta medida los hallazgos de Danaher et al. (2006) cuando llegan a la conclusión de que el contenido gráfico genera un resultado significativamente positivo, en su caso una mayor duración en el sitio web. 
Tabla 6

La eficacia publicitaria de los formatos publicitarios

\begin{tabular}{|c|c|c|c|c|c|c|}
\hline \multirow{3}{*}{ Medidas de eficacia } & \multicolumn{4}{|c|}{ Tipo de anuncio } & \multirow{3}{*}{$F$} & \multirow{3}{*}{ (p) } \\
\hline & \multicolumn{2}{|c|}{ Robapágina } & \multicolumn{2}{|c|}{ Contextual } & & \\
\hline & Media & D.T. & Media & D.T. & & \\
\hline Intensidad del recuerdo espontáneo & 1.429 & 0.878 & 1.335 & 0.806 & 2.740 & 0.098 \\
\hline Intensidad del recuerdo sugerido & 1.434 & 0.633 & 1.436 & 0.652 & 0.001 & 0.972 \\
\hline Reconocimiento & 2.325 & 0.715 & 2.178 & 0.823 & 7.897 & 0.005 \\
\hline Actitud hacia el anuncio & 3.763 & 1.317 & 2.753 & 1.207 & 138.394 & 0.000 \\
\hline Actitud hacia la marca & 3.252 & 1.386 & 2.855 & 1.303 & 16.085 & 0.000 \\
\hline Intención de compra & 2.810 & 1.586 & 2.720 & 1.569 & 0.707 & 0.401 \\
\hline
\end{tabular}

Al objeto de determinar en qué medida el tipo de blog en el que se inserta el anuncio influye en la eficacia del formato publicitario utilizado, se ha procedido a realizar un análisis de la influencia del entorno en que se ha insertado el anuncio (alta y baja implicación) con cada uno de los dos formatos publicitarios utilizados (robapágina y contextual). Como se desprende de los resultados que se recogen en la tabla 7, salvo para la intensidad del recuerdo sugerido, no se aprecian diferencias significativas en la eficacia de los dos formatos en función de que se inserten en un blog de alta o baja implicación. Estos resultados nos llevan a rechazar la hipótesis $\mathrm{H} 2$, en la que se establecía que en los anuncios en blogs de alta implicación presentan mejores resultados de eficacia en términos cognitivos, afectivos y conativos. Este resultado inesperado puede deberse al hecho de que la asignación de los individuos al tipo de blog (alta o baja implicación) fue totalmente aleatoria y no se ha controlado la posible incidencia en el diseño experimental del interés de las personas en el blog de cachivaches tecnológicos. Por otra parte, tampoco incluimos una variable en el cuestionario para medir el grado de interés que puedan tener las personas en blogs relacionados con cachivaches tecnológicos.

Tabla 7

Influencia del entorno de alta/baja implicación del blog en la eficacia publicitaria de los anuncios

\begin{tabular}{llccccccc}
\hline & & \multicolumn{6}{c}{ Grado de formato } \\
\cline { 3 - 8 } \multicolumn{1}{c}{ Medidas de eficacia } & Implicación & \multicolumn{5}{c}{ Robapágina } & \multicolumn{4}{c}{ Contextual } \\
\cline { 3 - 8 } & & Media & D.T. & $\begin{array}{c}F \\
(p)\end{array}$ & Media & D.T. & $\begin{array}{c}F \\
(p)\end{array}$ \\
\hline Intensidad del recuerdo & Alta & 1.417 & 0.833 & 0.092 & 1.279 & 0.751 & 2.205 \\
espontáneo & Baja & 1.442 & 0.917 & $(0.761)$ & 1.395 & 0.860 & $(0.138)$ \\
\hline Intensidad del recuerdo & Alta & 1.381 & 0.564 & 3.173 & 1.369 & 0.623 & 4.817 \\
sugerido & Baja & 1.488 & 0.695 & $(0.076)$ & 1.507 & 0.676 & $(0.029)$ \\
\hline
\end{tabular}




\begin{tabular}{lccccccc}
\hline \multirow{2}{*}{ Reconocimiento } & Alta & 2.341 & 0.698 & 0.221 & 2.153 & 0.837 & 0.421 \\
& Baja & 2.309 & 0.734 & $(0.639)$ & 2.205 & 0.809 & $(0.517)$ \\
\hline \multirow{2}{*}{ Actitud hacia el anuncio } & Alta & 3.814 & 1.292 & 0.674 & 2.768 & 1.258 & 0.079 \\
& Baja & 3.711 & 1.342 & $(0.412)$ & 2.736 & 1.153 & $(0.779)$ \\
\hline \multirow{2}{*}{ Actitud hacia la marca } & Alta & 3.325 & 1.425 & 0.912 & 2.833 & 1.326 & 0.120 \\
& Baja & 3.182 & 1.349 & $(0.340)$ & 2.879 & 1.280 & $(0.729)$ \\
\hline \multirow{2}{*}{ Intención de compra } & Alta & 2.840 & 1.685 & 0.156 & 2.800 & 1.663 & 1.290 \\
& Baja & 2.780 & 1.480 & $(0.693)$ & 2.630 & 1.458 & $(0.257)$ \\
\hline
\end{tabular}

Al objeto de analizar desde otra óptica la importancia que tiene el tipo de blog en el que se inserta un anuncio, en este trabajo se ha procedido a determinar en qué medida la actitud de los internautas hacia el blog se ve afectada por el tipo de blog. De esta forma, y tal y como se recoge en la tabla 8, se ha realizado un análisis ANOVA para determinar si existen o no diferencias significativas en alguna de las dos dimensiones que conforman la actitud de los internautas hacia el blog visitado (dimensión informativa y organizativa). Así, se observa que en entornos de alta implicación, los internautas perciben que se encuentran navegando en un entorno de naturaleza más informativa, práctica, y útil, y además que, a pesar de su carácter ampliamente informativo, no puede ser catalogado como un entorno más confuso, desordenado e irritante que un entorno en el que predomine la imagen frente al texto. Por consiguiente, el tipo de blog influye en las evaluaciones o actitudes de los internautas hacia el blog por el que navegan, siendo los de alta implicación los que generan mejores resultados. Estos resultados nos permiten aceptar la hipótesis H3 de que existen diferencias en la actitud hacia el sitio web del blog en función del entorno de alta o baja implicación del blog. Al mismo tiempo, se pone de manifiesto que internet es un medio en el que los individuos tienen un papel activo y que es considerado como una fuente de información práctica y útil.

Tabla 8

La actitud hacia el tipo de blog

\begin{tabular}{lccccccc}
\hline & \multicolumn{3}{c}{$\begin{array}{c}\text { Dimensión } \\
\text { informativa }\end{array}$} & & \multicolumn{3}{c}{$\begin{array}{c}\text { Dimensión } \\
\text { organizativa }\end{array}$} \\
\cline { 2 - 8 } & Media & D.T. & $\begin{array}{c}F \\
(p)\end{array}$ & Media & D.T. & $\begin{array}{c}F \\
(p)\end{array}$ \\
\hline ALTA & 4.437 & 1.369 & 142.951 & 2.526 & 1.427 & 10.806 \\
BAJA & 3.325 & 1.366 & $(0.000)$ & 2.841 & 1.382 & $(0.001)$ \\
\hline
\end{tabular}

En la tabla 9 se recogen los resultados del análisis realizado para conocer en qué medida la actitud de los individuos hacia el blog influye en la eficacia publicitaria. Como se puede observar, las medidas vinculadas con la memoria no se ven afectadas, no ocurriendo lo mismo con las de tipo afectivo y conativo. De esta forma, cuando los individuos perciben que se encuentran en un entorno más informativo, práctico y útil, los anuncios presentan mejores re- 
sultados en términos de actitud hacia el anuncio, actitud hacia la marca, e incluso, intencionalidad de compra. En cambio, y como era de esperar, cuando se percibe al entorno como más confuso, desordenado e irritante, las medidas afectivas hacia el anuncio son peor evaluadas y la intencionalidad de compra no se ve afectada. Por tanto, la hipótesis $\mathrm{H} 4$ se puede aceptar en lo se refiere a la influencia de la actitud hacia el sitio web del blog sobre las medidas de eficacia publicitaria de carácter afectivo y conativo, pero no en las de carácter cognitivo.

Tabla 9

Influencia de la actitud hacia el blog en las medidas de eficacia publicitaria

\begin{tabular}{lcccc}
\hline \multirow{2}{*}{\multicolumn{1}{c}{ Medidas de eficacia }} & \multicolumn{2}{c}{$\begin{array}{c}\text { Dimensión } \\
\text { informativa }\end{array}$} & \multicolumn{2}{c}{$\begin{array}{c}\text { Dimensión } \\
\text { organizativa }\end{array}$} \\
\cline { 2 - 5 } & $r$ & $p$ & $r$ & $p$ \\
\hline Intensidad del recuerdo espontáneo & 0.018 & 0.587 & -0.013 & 0.709 \\
\hline Intensidad del recuerdo sugerido & -0.037 & 0.278 & 0.010 & 0.765 \\
\hline Reconocimiento & -0.033 & 0.328 & -0.022 & 0.527 \\
\hline Actitud hacia el anuncio & 0.321 & 0.000 & -0.104 & 0.002 \\
\hline Actitud hacia la marca & 0.349 & 0.000 & -0.114 & 0.002 \\
\hline Intención de compra & 0.287 & 0.000 & -0.040 & 0.235 \\
\hline
\end{tabular}

Otro de los factores recogidos en la literatura que influyen en la eficacia publicitaria es el grado de implicación del individuo con el producto anunciado. En la tabla 10 se observa claramente cómo esta variable incide claramente en la eficacia de los anuncios en términos cognoscitivos, afectivos y conativos. De esta forma, cuando un individuo muestra un mayor grado de implicación hacia un producto, medido en términos de interés por el mismo, se observa que el anuncio es más recordado, es mejor evaluado, genera una actitud más positiva hacia la marca e, incluso, provoca una mayor intencionalidad de compra. Por tanto, se acepta la hipótesis H5, en la que se ponía de manifiesto que el grado de implicación de un visitante con el producto anunciado en un blog tiene una relación significativa y positiva con las medidas de eficacia cognitivas, afectivas y conativas.

Tabla 10

Influencia del grado de involucración con el producto en las medidas de eficacia publicitaria

\begin{tabular}{lcc}
\hline \multicolumn{1}{c}{ Medidas de eficacia } & $r$ & $p$ \\
\hline Intensidad del recuerdo espontáneo & 0.134 & 0.000 \\
\hline Intensidad del recuerdo sugerido & 0.066 & 0.052 \\
\hline Reconocimiento & 0.043 & 0.207 \\
\hline Actitud hacia el anuncio & 0.304 & 0.000 \\
\hline Actitud hacia la marca & 0.373 & 0.000 \\
\hline Intención de compra & 0.572 & 0.000 \\
\hline
\end{tabular}


Para analizar si el uso de internet y el acceso a páginas tipo blog pueden influir o no en la eficacia cognitiva de los anuncios, se ha procedido a determinar los coeficientes de correlación entre estas dos variables y cada una de las medidas de eficacia publicitaria de carácter cognitivo (véase tablas 11 y 12). Los datos recogidos en dichas tablas ponen de manifiesto que el grado de uso de internet y de blogs no genera mayor recuerdo ni reconocimiento de los anuncios incluidos en el blog. Por tanto, estos resultados ponen de manifiesto que se deben aceptar las dos hipótesis planteadas al respecto (H6 y H7). No obstante, y de forma exploratoria también se procedió a analizar en qué medida estas variables influían en el éxito afectivo y conativo de los anuncios. Como se puede observar en la tabla 11, el nivel de uso de internet sólo afecta a las medidas afectivas, pero de forma negativa. Es decir, cuanto mayor sea la frecuencia de uso de internet de una persona sus evaluaciones hacia los anuncios a los que es expuesta, así como hacia las marcas anunciadas son más negativas. Este resultado puede ser considerado como un efecto negativo de la saturación publicitaria del medio internet. En cuanto a la influencia de la frecuencia de acceso a páginas tipo blog por parte de los individuos sobre las medidas afectivas y conativas de eficacia publicitaria, los resultados de la tabla 12 indican que no afecta. Este resultado, que contrasta con el obtenido con la frecuencia de acceso a internet, puede explicarse por el hecho de que no se ha generado aún entre sus visitantes este sentimiento de rechazo hacia la publicidad dado que no se trata de páginas en la que exista saturación publicitaria.

Tabla 11

Influencia del grado de uso de internet en las medidas de eficacia publicitaria

\begin{tabular}{lcc}
\hline \multicolumn{1}{c}{ Medidas de eficacia } & $r$ & $p$ \\
\hline Intensidad del recuerdo espontáneo & 0.012 & 0.727 \\
\hline Intensidad del recuerdo sugerido & 0.016 & 0.640 \\
\hline Reconocimiento & 0.021 & 0.539 \\
\hline Actitud hacia el anuncio & -0.153 & 0.000 \\
\hline Actitud hacia la marca & -0.118 & 0.001 \\
\hline Intención de compra & -0.067 & 0.048 \\
\hline
\end{tabular}

Tabla 12

Influencia del uso de blogs en las medidas de eficacia publicitaria

\begin{tabular}{lcc}
\hline \multicolumn{1}{c}{ Medidas de eficacia } & $r$ & $p$ \\
\hline Intensidad del recuerdo espontáneo & -0.032 & 0.353 \\
\hline Intensidad del recuerdo sugerido & 0.006 & 0.858 \\
\hline Reconocimiento & -0.014 & 0.679 \\
\hline Actitud hacia el anuncio & -0.029 & 0.394 \\
\hline Actitud hacia la marca & -0.001 & 0.985 \\
\hline Intención de compra & 0.012 & 0.731 \\
\hline
\end{tabular}


Finalmente, y al objeto de conocer en qué medida la duración de la visita al sitio web influye en la eficacia de los anuncios, se ha procedido, en primer lugar, a realizar un análisis descriptivo del tiempo dedicado a visitar la página. De esta forma, el $35.8 \%$ de los encuestados dedicó menos de 6 minutos a navegar en el blog, el 46.0\%, ha dedicado entre 6 y 10 minutos y el $18.2 \%$ ha dedicado más de 10 minutos. En la tabla 13 se recogen los resultados del análisis realizado para conocer en qué medida la duración de la visita al blog ha influido en la eficacia de los anuncios. Como se desprende de estos resultados, la intensidad del recuerdo sugerido y el reconocimiento presentan diferencias significativas, de tal forma que a mayor duración de la visita mayor es el efecto cognitivo de los anuncios sobre los individuos. Así mismo, este mismo efecto se aprecia en la actitud hacia la marca, lo que demuestra la necesidad de que para poder emitir una evaluación de una marca es necesario que el individuo interactúe con los mensajes de la marca. Sobre la base de estos resultados se acepta parcialmente la hipótesis $\mathrm{H} 8$.

Tabla 13

Influencia de la duración de la visita al sitio web en la eficacia publicitaria de los anuncios

\begin{tabular}{|c|c|c|c|c|}
\hline Medidas de eficacia & Grupo & Media & D.T. & $\begin{array}{c}F \\
(p)\end{array}$ \\
\hline \multirow{3}{*}{ Intensidad del recuerdo espontáneo } & Alta & 1.392 & 0.858 & \multirow{3}{*}{$\begin{array}{c}1.479 \\
(0.228)\end{array}$} \\
\hline & Media & 1.429 & 0.879 & \\
\hline & Baja & 1.319 & 0.783 & \\
\hline \multirow{3}{*}{ Intensidad del recuerdo sugerido } & Alta & 1.557 & 0.682 & \multirow{3}{*}{$\begin{array}{c}3.649 \\
(0.026)\end{array}$} \\
\hline & Media & 1.419 & 0.608 & \\
\hline & Baja & 1.394 & 0.658 & \\
\hline \multirow{3}{*}{ Reconocimiento } & Alta & 2.291 & 0.751 & \multirow{3}{*}{$\begin{array}{c}3.411 \\
(0.033)\end{array}$} \\
\hline & Media & 2.308 & 0.752 & \\
\hline & Baja & 2.161 & 0.804 & \\
\hline \multirow{3}{*}{ Actitud hacia el anuncio } & Alta & 3.353 & 1.376 & \multirow{3}{*}{$\begin{array}{c}0.444 \\
(0.641)\end{array}$} \\
\hline & Media & 3.264 & 1.352 & \\
\hline & Baja & 3.227 & 1.367 & \\
\hline \multirow{3}{*}{ Actitud hacia la marca } & Alta & 3.324 & 1.315 & \multirow{3}{*}{$\begin{array}{c}5.902 \\
(0.003)\end{array}$} \\
\hline & Media & 3.072 & 1.367 & \\
\hline & Baja & 2.836 & 1.341 & \\
\hline \multirow{3}{*}{ Intención de compra } & Alta & 2.911 & 1.537 & \multirow{3}{*}{$\begin{array}{c}0.967 \\
(0.381)\end{array}$} \\
\hline & Media & 2.767 & 1.600 & \\
\hline & Baja & 2.697 & 1.572 & \\
\hline
\end{tabular}

\section{CONCLUSIONES}

El gran auge que ha experimentado en los últimos años las páginas web tipo blog o bitácora y la falta de estudios en la literatura sobre la eficacia de los anuncios publicitarios en el 
entorno del blog nos ha llevado a plantear el presente trabajo cuyo objetivo se ha centrado en medir la eficacia de dos formatos de publicidad (robapáginas y contextual), analizando, al mismo tiempo, cómo influyen los factores relacionados con grado de implicación del blog, actitud hacia el blog, implicación con el producto anunciado, grado de uso de internet y páginas web tipo blog por parte del internauta y duración de la visita en el blog.

Desde un punto de vista metodológico y de acuerdo con los fines propuestos, se realizó una experimentación 2x2 en el que se combinaron dos blogs (alta versus baja implicación) y dos formatos de anuncios on-line (robapáginas versus contextual) a través del diseño de cuatro blogs relacionados con productos tecnológicos, tema congruente con los productos anunciados de carácter también tecnológico.

Los resultados obtenidos ponen de manifiesto que en general el formato de anuncio robapáginas es más efectivo que el formato contextual en términos cognitivos y afectivos, aunque no existen diferencias en la intención de compra que generan. Por tanto, se aporta una evidencia empírica que demuestra que en las páginas web tipo blog los formatos en los que se combinan textos e imágenes generan un mayor nivel de recuerdo y actitudes más positivas hacia el anuncio y hacia la marca.

Por otra parte, también se observa que los blog destinados a públicos de alta implicación se perciben como más informativos, prácticos y útiles frente a los de baja implicación que generan una actitud más negativa. Ello es debido al papel activo que juegan los internautas en estas páginas que les hace considerar el blog como una fuente de información práctica y útil. La actitud que tienen los internautas hacia la página blog influye en la actitud hacia los anuncios y en la intención de compra que genera el anuncio. De esta forma, cuando se percibe que el blog es informativo, práctico y útil, los anuncios generan mejores resultados en términos de actitud hacia el anuncio, actitud hacia la marca e, incluso, intencionalidad de compra. La implicación con el producto anunciado es quizás la variable que más influencia ejerce en la eficacia de los anuncios on-line, ya que cuanto más implicado esté el internauta en los productos que se anuncian, el anuncio es más recordado, mejor evaluado, se genera una actitud más positiva hacia la marca e, incluso, mayor es la intencionalidad de compra. Sin embargo, la frecuencia de uso de internet por parte de los internautas influye negativamente en la eficacia de los anuncios a nivel afectivo, lo cual puede ser debido a la saturación publicitaria en el medio internet que genera claros efectos negativos. Por el contrario, la frecuencia de uso de páginas web tipo blog no influye en la eficacia de los anuncios, por lo que cabría pensar que estamos ante un soporte en el que todavía no se ha hecho excesivo uso de la publicidad. Finalmente, y como era de esperar, la duración de la visita en el blog es un factor que también afecta a la eficacia publicitaria de los anuncios insertados en los blogs.

Las principales implicaciones prácticas del presente trabajo se centran en el diseño de los anuncios on-line en el contexto de las páginas web tipo blog. Sobre la base de los resultados es aconsejable utilizar formatos de anuncios que combinen textos e imágenes, ya que son más eficaces que los que sólo introducen texto. Igualmente, es preferible insertar los anuncios publicitarios en blogs caracterizados por mucho texto y destinados a públicos de alta implicación que en blogs destinados a públicos de baja implicación y basados en contenidos dinámicos como vídeos y fotos, ya que la actitud hacia el blog influye en la actitud hacia el anuncio. También es importante hacer una adecuada selección del blog en el que se inserten los anuncios en función del target al que vayan dirigidos, ya que la involucra- 
ción con el producto es quizás la variable que más influye en la eficacia de los anuncio. No obstante, es importante no hacer un uso excesivo de la publicidad en este tipo de páginas web, en las que todavía no existe una gran saturación publicitaria. Así mismo, también es recomendable incluir en el blog elementos que incrementen el grado de interacción del individuo con el mismo para conseguir aumentar la duración de la visita, ya que se trata de un factor que incide positivamente en el éxito cognitivo de los anuncios.

Finalmente, y en lo que a las limitaciones del trabajo se refiere, el ámbito geográfico de la investigación empírica sólo permite generalizar los resultados de los análisis a la población de la que procede la muestra, por lo que sería conveniente replicar esta investigación en otras zonas geográficas. Por otra parte, el hecho de que el diseño experimental se haya centrado en dos tipos de formatos de anuncios constituye otra limitación que hace aconsejable ampliar esta línea de investigación a otros formatos de anuncios, así como analizar otros factores que puedan influir en la eficacia de los anuncios.

\section{REFERENCIAS BIBLIOGRÁFICAS}

AIMC-EGM (2009): Audiencia de internet. Febrero/Marzo 2009. Disponible en http://www.aimc.es ALIANZO (2007): Ranking de blogs - España. Disponible en http://www.alianzo.com/top-blogs/ spain

ALT64 DIGITAL (2005): Estudio eyetrack medios España: Análisis del comportamiento visual de los internautas y la efectividad de la publicidad online. Disponible en http://www.alt64.com/ extras/Eyetracking Media Espana.pdf

BALTAS, G. (2003): "Determinants of internet advertising effectiveness: an empirical study”, International Journal of Market Research, Vol. 45 (4), pp. 505-513.

BRIGGS, R. Y HOLLIS, N. (1997): "Advertising on the web: is there response before clickthrough?", Journal of Advertising Research, Vol. 37 (2), pp. 33-45.

BROWN, M. (2002): "The use of banner advertisements with pull-down menus: a copy testing approach", Journal of Interactive Advertising, Vol. 2 (2), http://jiad.org/article24.

BURNS, K.S. Y LUTZ, R.J. (2006): "The function of format: Consumer responses to six on-line advertising formats", Journal of Advertising, Vol. 35 (1), pp. 53-63.

CHANDON J.L. Y CHTOUROU M.S. (2005): "Factors affecting click-through", en Haugtvedt, C.P.; Machleit, K.A. y Yalch, R. (eds.), In Online consumer psychology: understanding and influencing consumer behavior in the virtual world. Routledge, pp. 143-163.

CHANDON J.L., CHTOUROU M.S. Y FORTÍN D.R. (2003): "Effects of configuration and exposure levels on responses to web advertisements", Journal of Advertising Research, Vol. 43 (2), pp. 217-229.

CHEUNG, RONNIE C.T. (2006): "Case study of a successful internet advertising strategy in Hong Kong: a portal for teenagers", Marketing Intelligence \& Planning, Vol. 24 (4), pp. 393-405.

CHO, C.H. (2003): "Factors influencing the clicking of banner ads on the WWW", CyberPsychology and Behavior, Vol. 6 (2), pp. 201-215.

CHO, C.H., Y CHEON, J. (2004): "Why do people avoid advertising on the internet?", Journal of Advertising, Vol. 33 (4), pp. 89-97.

CHTOUROU, M.S., CHANDON, J.L. Y ZOLLINGER, M. (2001): "Effect of price information and promotion on click.through rates for internet banners", Journal of Euromarketing, Vol. 11 (2), pp. 23-40.

DAHLEN, M. (2001): "Banner advertisements through a new lens", Journal of Advertising Research, Vol. 41 (July/August), pp. 23-30. 
DAHLEN, M. (2002): “Thinking and feeling on the World Wide Web: the impact of product type and time on World Wide Web advertising effectiveness", Journal of Marketing Communication, Vol. 8, pp. 115-125.

DAHLÉN, M. Y BERGENDAHL, J. (2001): "Informing and transforming on the web: an empirical study of response to banner ads for functional and expressive products", International Journal of Advertising, Vol. 20, pp. 189-205.

DAHLEN, M., ROSENGREN, S. Y RASCH, A. (2003): "Love at first site? A study of website advertising effectiveness", Journal of Advertising Research, Vol. 43 (1), pp. 25-33.

DANAHER P.J. Y MULLARKEY, G.W. (2003): "Factors affecting online advertising recall: A study of students", Journal of Advertising Research, Vol. 43 (3), pp. 252-267.

DANAHER P.J., MULLARKEY, G.W. Y ESSEGAIER, S. (2006): "Factors affecting web site duration: a cross-domain analysis", Journal of Marketing Research, Vol. XLIII (May), pp. 182-194.

DREZE, X. Y HUSSHERR, F. (2003): “Internet advertising: is anybody watching?", Journal of Interactive Marketing, Vol. 17 (4), pp. 8-23.

GATARSKI, R. (2002): "Breed better banners: design automation through on-line interaction", Journal of Interactive Marketing, Vol. 16 (1), pp. 2-13.

GEORGE, J.F. (2002): "Influences on the intent to make internet purchases", Internet Research: Electronic Networking Applications and Policy, Vol. 12 (2), pp. 165-180.

GOLDSMITH, R.E. Y LAFFERTY B.A. (2002): "Consumer response to web sites and their influence on advertising effectiveness"., Internet Research: Electronic Networking Applications and Policy, Vol. 12 (4), pp. 318-328.

GONG, W. Y MADDOX, L.M. (2003): "Measuring web advertising effectiveness in China", Journal of Advertising Research, Vol. 43 (1), pp. 34-49.

HOLLIS, N. (2005): "Ten years of learning on how online advertising builds brands", Journal of Advertising Research, Vol. 45 (2), pp. 255-268.

HUPFER, M.E. Y GREY, A. (2005): "Getting something for nothing: the impact of a sample offer and user mode on banner ad response", Journal of Interactive Advertising, Vol. 6 (1), pp. 149-164.

INFOADEX. Estudios infoadex de la inversión publicitaria en españa. Disponible en www.Infoadex.Es/infoadex.Asp.

LEE, J.G. Y THORSON, E. (2009): "Cognitive and emotional processes in individuals and commercial web sites”, Journal of Business Psychology, Vol. 24 (1), pp. 105-115.

LEONG, E.K.F.; HUANG, X. Y STANNERS, P.J. (1998): "Comparing the effectiveness of the web site with traditional media”., Journal of Advertising Research, Vol. 38 (5), pp. 44-51.

LOHTIA, R., DONTHU, N. Y HERSHBERGER, E.K. (2003): "The impact of content and design elements on banner advertising click-through rates", Journal of Advertising Research, Vol. 43 (4), pp. 410-418.

MANCHANDA, P., DUBÉ, J.P., GOH, K.Y. Y CHINTAGUNTA, P.K. (2006): “The effect of banner advertising on internet purchasing”, Journal of Marketing, Vol. XLIII (February), pp. 98-108.

MENON, S. Y SOMAN, D. (2002): "Managing the power of curiosity for effective web advertising strategies", Journal of Advertising, Vol. 31 (3), pp. 1-14.

MILLER, S.E. (1996): Civilizing cyberspace: policy, power, and the information superhighway. New York: ACM Press.

NEWMAN, E.J., STEM JR., D.E. Y SPORT, D.E. (2004): "Searching advertising placement in cyberspace”, Industrial Management \& Data System, Vol. 104 (3), pp. 273-281.

O'REILLY, T. (2005): What is Web 2.0? Design patterns and business models for the next generation of software. Disponible en julio de 2007 en http://www.oreillynet.com/pub/a/oreilly/tim/ news/2005/09/30/what-is-web-20.html

PAVLOU, P.A. Y STEWART, D.W. (2000): "Measuring the effects and effectiveness of interactive advertising: a research agenda", Journal of Interactive Advertising, Vol. 1 (1), http://jiad.org/ article6. 
PETTY, R.E. Y CACIOPPO, J.T. (1986): Communication and persuasion: central and peripheral routes to attitudes change. New York: Springer.

PIETERS, R. Y WEDEL, M. (2004): “Attention capture and transfer in advertising: brand, pictorial, and text-size effects", Journal of Marketing, Vol. 68 (April), pp. 36-50.

ROBINSON, H., WYSOCKA, A. Y HAND, C. (2007): "Internet advertising effectiveness. The effect of design on click-through rates for banners ads", International Journal of Advertising, Vol. 26 (4), pp. 527-541.

SAN JOSÉ CABEZUDO, R.; GUTIÉRREZ ARRANZ, AM. Y GUTIÉRREZ CILLÁN, J. (2004): "Determinantes de la eficacia publicitaria del sitio web. Una aplicación del ELM", Revista Española de Investigación y Marketing-ESIC, Vol. 8 (2), pp. 93-121.

SAN MARTÍN GUTIÉRREZ S. Y LÓPEZ CATALÁN B. (2010): "Posibilidades de la compraventa b2c por teléfono móvil en comparación con internet", Revista Cuadernos de Gestión Vol. 10. N ${ }^{\circ}$ 1, pp. 17-34."

SCHLOSSER, A.E., SHAVITT S. Y KANFER A. (1999): "Survey of internet users' attitudes toward internet advertising", Journal of Interactive Marketing, Vol. 13 (3), pp. 34-54.

SHANDASANI, P.N., TAN, J. Y ANDREA J.S.S. (2001): "Location, location, location: insights for advertising placements on the web", Journal of Advertising Research, Vol. 41 (4), pp. 6-21.

SHEN, F. (2002): "Banner advertisement pricing, measurement, and pretesting practices: perspectives from interactive agencies", Journal of Advertising, Vol. 31 (3), pp. 59-67.

STEVENSON, J.S., BRUNER II, G.C. Y KUMAR, A. (2000): "Web page background and viewer attitudes", Journal of Advertising Research, Vol. 40 (1/2), pp. 29-34.

SUNDAR, S. S. Y KALYANARAMAN, S. (2004): "Arousal, memory, and impression-formation effects of animation speed in web advertising", Journal of Advertising, Vol. 33 (1), pp. 7-17.

YAVEROGLU, I. Y DONTHU, N. (2008): "Advertising repetition and placement issues in on-line environments", Journal of Advertising, Vol. 37 (2), pp. 31-43.

YOON, S.J. Y KIM J. H. (2001): "Is the internet more effective than traditional media? Factors affecting the choice of media", Journal of Advertising Research, Vol. 41 (6), pp. 53-60. 